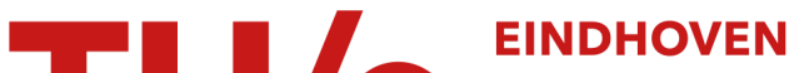 \\ UNIVERSITY OF \\ TECHNOLOGY
}

\section{The shrinkage of hardening cement paste and mortar}

Citation for published version (APA):

Haas, de, G. D., Kreijger, P. C., Niël, E. M. M. G., Slagter, J. C., Stein, H. N., Theissing, E. M., \& Wallendael, van, M. (1975). The shrinkage of hardening cement paste and mortar. Cement and Concrete Research, 5(4), 295-319. https://doi.org/10.1016/0008-8846(75)90087-3

DOI:

10.1016/0008-8846(75)90087-3

Document status and date:

Published: 01/01/1975

\section{Document Version:}

Publisher's PDF, also known as Version of Record (includes final page, issue and volume numbers)

\section{Please check the document version of this publication:}

- A submitted manuscript is the version of the article upon submission and before peer-review. There can be important differences between the submitted version and the official published version of record. People interested in the research are advised to contact the author for the final version of the publication, or visit the $\mathrm{DOI}$ to the publisher's website.

- The final author version and the galley proof are versions of the publication after peer review.

- The final published version features the final layout of the paper including the volume, issue and page numbers.

Link to publication

\section{General rights}

Copyright and moral rights for the publications made accessible in the public portal are retained by the authors and/or other copyright owners and it is a condition of accessing publications that users recognise and abide by the legal requirements associated with these rights.

- Users may download and print one copy of any publication from the public portal for the purpose of private study or research.

- You may not further distribute the material or use it for any profit-making activity or commercial gain

- You may freely distribute the URL identifying the publication in the public portal.

If the publication is distributed under the terms of Article 25fa of the Dutch Copyright Act, indicated by the "Taverne" license above, please follow below link for the End User Agreement:

www.tue.nl/taverne

Take down policy

If you believe that this document breaches copyright please contact us at:

openaccess@tue.nl

providing details and we will investigate your claim. 
CEMENT and CONCRETE RESEARCH. Vo1. 5, pp. 295-320, 1975. Pergamon Press, Inc. Printed in the United States.

THE SHRINKAGE OF HARDENING CEMENT PASTE AND MORTAR

G.D. de Haas, P.C. Kreijger, E.M.M.G. Niël, J.C. Slagter, H.N. Stein, E.M. Theissing, M. van Wallendael*

(Rec'd. Sept. 26, 1973; in final form April 9, 1975)

(Refereed)

ABSTRACT

this paper is an abstract from the report of the commission B10: "The influence of the shrinkage of cement on the shrinkage of concrete", of the Netherlands Committee for Concrete Research.

Measurements of pulse velocity, volume shrinkage and heat of hydration on hardening portland cement support the idea that the formation of ettringite is an important link in the mechanism of shrinkage in the plastic stage of cement paste and mortar.

Mechanical tests on prisms of $4 \times 4 \times 16 \mathrm{~cm}^{3}$ gave some information about the difference in sensitivity to surface corrosion of different types of cement.

Das vorliegende Bericht gibt ein kurzes Uebersicht von den Arbeit des Ausschusz B10 von dem Niederländischen Verein für Betonprüfung, hinsichtlich die Einflusz des Zementschwindens auf das Schwinden des Betons.

Die Prüfung von Pulsgeschwindigkeit, Volumeschwindung und Hydratationswärme an erstarrende Paste von Portland Zement während den ersten drei Tagen stärkte die Auffassung dasz die Bildung von Ettringit während der plastischen Phase von Zementpaste und Mörtel sehr wichtig ist zur Erklärung des Mechanismus des Schwindprozesses. Auch mechanische Prüfungen an erstarrten Zement- und Mörtelprismen wurden durchgeführt zur Erklärung des Schwindprozesses.

Affiliations of the authors can be obtained from CUR, P.0. Box 61, Zoetermeer, The Netherlands. 


\section{Introduction}

The purpose of this article is to introduce to a greater public the findings of the commission $B 10$ of the Netherlands Committee for Concrete Research (CUR) which studied the influence of the shrinkage of cement on the shrinkage of concrete. In this article only the main points of the study will be discussed.

The shrinkage of cement paste during hardening is caused by chemical reactions of the clinker minerals with water during the first hours. At a later stage it is caused by changes in the water content of the hardened paste.

The purpose of the study was to obtain more knowledge about the changes in volume in the first stage. To do this the following properties were measured during the hardening process:

a) Heat evolution rate (with a conduction calorimeter)

b) Velocity of ultrasonic pulses

c) Volume shrinkage

Next to these measurements also the strength and the shrinkage of the hardened prisms, made with different types of cement, were measured.

\section{Experimental}

The heat evolution rate calculated per gram cement was measured using Lerch's method (1) by means of an isothermal conduction calorimeter as described by Stein (2). The first peak was not measured because the mixing procedure of 2 minutes stirring, 3 minutes rest, 2 minutes stirring was done outside the calorimeter.

The velocity of pulses in hardening cement postes and mortars was measured with a Cawkell UCT 2 apparatus at $40 \mathrm{kHz}$. The specimen was placed in a thin rubber container between the piëzo 
electric measuring crystals of the instrument. The crystals were mounted on a fixed distance; the specimen filled exactly the space between them.

Changes in volume of a hardening paste or mortar due to chemical transformations were measured on a specimen of \pm 600 grams placed in a water-tight rubber cover to exclude the influence of drying or water-uptake. This sealed specimen was placed in a vessel completely filled with water of $20 \pm 0.1^{\circ} \mathrm{C}$. The vessel was connected with a tube filled with water to a beaker on the scale of a Mettler bolance. When changes of volume occurred the rubber cover followed these changes and water was sucked out or pressed into the beaker. The changes in weight of the filled beaker were recorded and from these the changes in volume of the specimen were calculated. In these experiments the same batch of portland cement class $A$ was used.

The chemical and calculated mineralogical composition of this portland cement is given in table 1 .

\section{Results and Discussion}

\section{Heat Evolution Rate}

The influence of increasing amounts of the various clinker minerals, of water, of the addition of sand and of the time of aerating the

\section{TABLE}

Analysis of a Homogeneous Batch of Dutch Portland Cement.

\begin{tabular}{|c|c|c|c|}
\hline Chemical Analysis & $\%$ by weight & Mineralogical Composition & in \% by weig \\
\hline $\begin{array}{l}\mathrm{L} .0 . \mathrm{I} \cdot 1000{ }^{\circ} \mathrm{C} \\
\mathrm{SiO}_{2} \\
\mathrm{AL}_{2} \mathrm{O}_{3} \\
\mathrm{Fe}_{2} \mathrm{O}_{3} \\
\mathrm{CoO} \text { total } \\
\mathrm{MgO} \\
\mathrm{Na}_{2} \mathrm{O} \\
\mathrm{K}_{2} \mathrm{O} \\
\mathrm{SO}_{3} \\
\text { Total }\end{array}$ & $\begin{array}{r}1.0 \\
22.5 \\
5.5 \\
2.6 \\
64.5 \\
1.2 \\
0.1 \\
0.5 \\
2.1 \\
100.0\end{array}$ & $\begin{array}{l}\mathrm{L} .0 . \mathrm{I} .1000{ }^{\circ} \mathrm{C} \\
\mathrm{C}_{2} \mathrm{~S} \\
\mathrm{C}_{3} \mathrm{~S} \\
\mathrm{C}_{3} \mathrm{~A} \\
\mathrm{C}_{4} \mathrm{AF} \\
\mathrm{CaO} \text { free } \\
\mathrm{MgO} \\
\mathrm{Na}_{2} \mathrm{O} \\
\mathrm{K}_{2} \mathrm{O} \\
\mathrm{CaSO}{ }_{4} \\
\text { Total } \\
\end{array}$ & $\begin{array}{c}1.0 \\
30.8 \\
44.8 \\
10.2 \\
7.9 \\
- \\
1.2 \\
0.1 \\
0.5 \\
3.6 \\
100.1 \\
\end{array}$ \\
\hline & & $\begin{array}{l}\text { Specific Surface cm } 2 / \mathrm{g} \\
\text { Specific Weight }\end{array}$ & $\begin{array}{r}2900 \\
3,11 \\
\end{array}$ \\
\hline
\end{tabular}


cement with air containing carbon dioxide and water vapour on the flow of heat was studied.

The influence of the specific surface and the amount of alkali of the cement, which are thought to be large, have not been investigated. In general three periods of increasing and decreasing heat evolution (peaks) can be observed when the hardening of portland cement is studied with an isothermal conduction calorimeter. On the decreasing branch of the second peak after \pm 18 hours a small hump or shoulder can sometimes be seen (Figure 1). The cause of this hump is not clear; it is frequently attributed to both $\beta-C_{2} S$ and $C_{4} A F$.

The magnitude of the peaks, and the time at which they occur, in the first place depends on the mineralogical composition and fineness of the cement. In table 2 the changes in time and height of the second and third peak are summarized. The exact values of time shift and peak height are not given because they depend too much on the mineralogical composition of the clinker used.

The influence of $\mathrm{C}_{3} \mathrm{~S}$ added (Figure 2) on the second peak is rather clear: a larger surface of $\mathrm{C}_{3} \mathrm{~S}$ is exposed to water, so more reaction heat can be evolved.

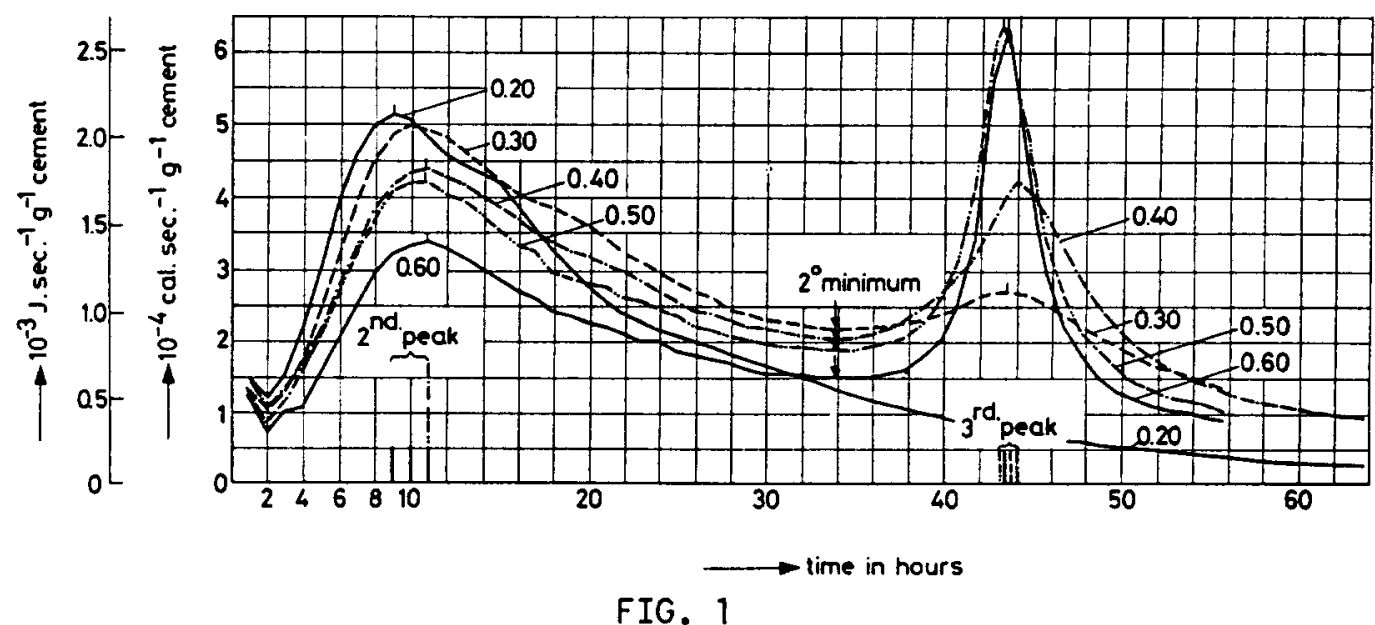

Influence of the $w / c$ ratio on the heat development of portland cement class $A$ 
TABLE 2

The Influence on Time of Occurrence and Height of the Peaks in the Heat Flow Curve by varying the Composition

\begin{tabular}{|l|c|c|c|l|}
\hline \multirow{2}{*}{$\begin{array}{l}\text { Increasing } \\
\text { Amounts of }\end{array}$} & \multicolumn{2}{|c|}{ Second Peak } & \multicolumn{2}{|c|}{ Third Peak } \\
\cline { 2 - 5 } & Height & Time & Height & Time \\
\hline$C_{3} A$ & - & - & higher & sooner \\
$C_{3} S$ & higher & - & - & - \\
$C_{a S O}$ & - & - & lower & loter \\
water & lower & loter & higher & sooner \\
quartz sand & - & - & lower & sooner \\
aerating time & lower & - & higher & sooner \\
\hline
\end{tabular}

- = no distinct influence

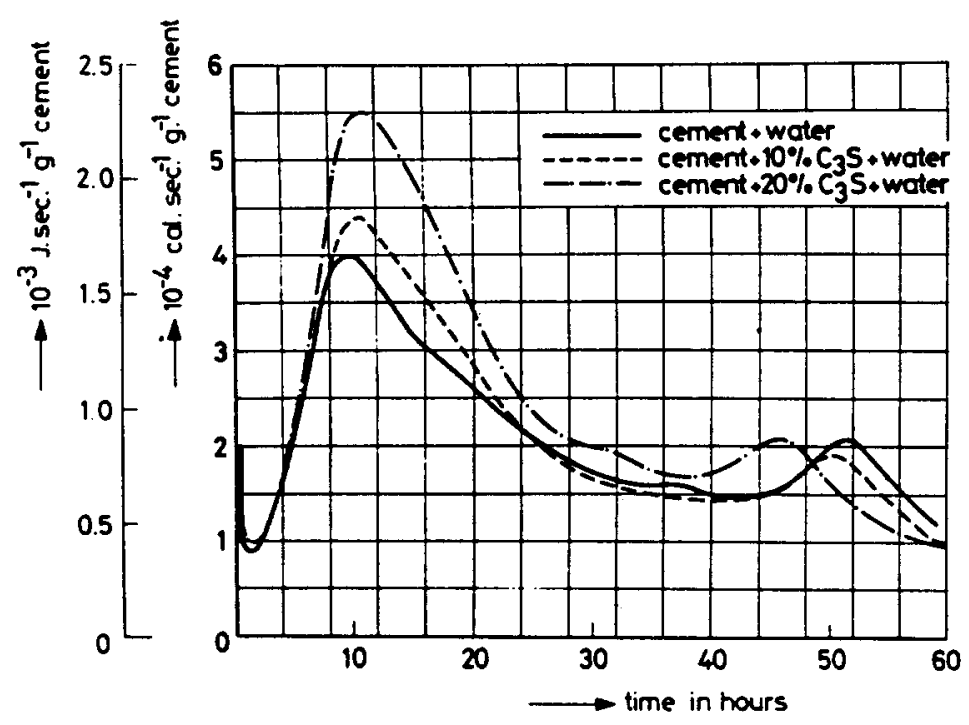

FIG. 2

Influence of the addition of $\mathrm{C}_{3} \mathrm{~S}$ on the heat development of portland cement

Addition of more $C_{3} A$ (see Figure 3 ) gives a larger sulphate consumption during the first peak, the grains become covered with ettringite crystals through which the reaction rate becomes low (appr. at 2 hours in Figure 3 ). The ettringite layer is less thick with more $C_{3} A$ because the same amount of gypsum is availableTherefore the layer is more permeable for water. 

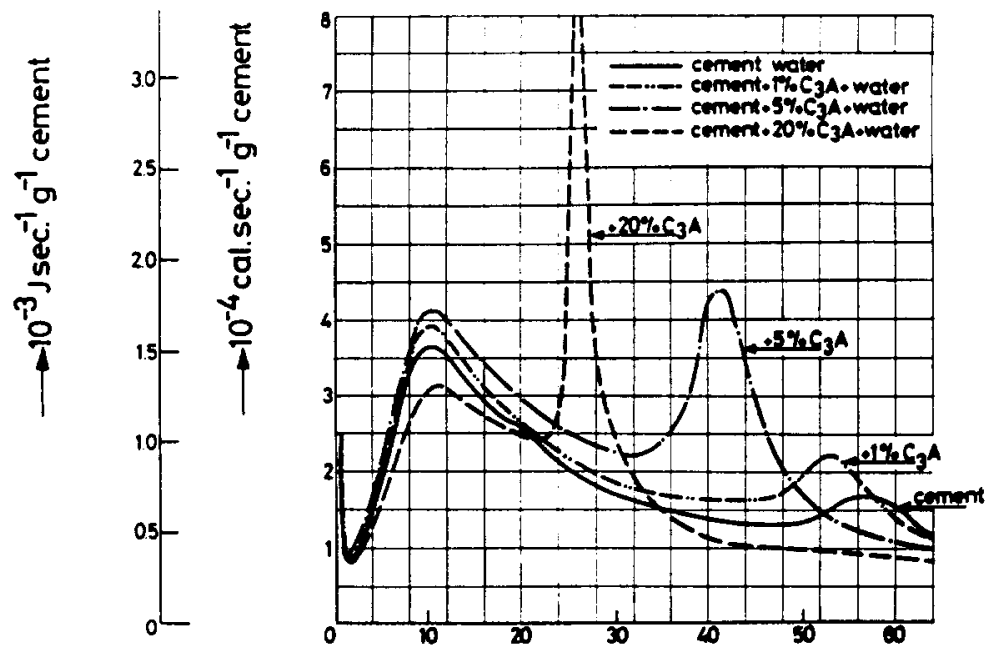

\section{$\longrightarrow$ time in hours}

FIG。 3

Influence of $\mathrm{C}_{3} \mathrm{~A}$ addition on the heat development of portland cement

This results, either according to the "scaling off" mechanism (2),

(3) or by chemical destruction

(4),

(5), in a faster consumption of sulphate until the stage is reached at which all sulphate is consumed. This stage will be reached in shorter time and a new $C_{3} A$ hydration peak (the third peak) is formed sooner. The influence of the addition of gypsum can be desribed by the same mechanism with the opposite result; the third peak is developed later.

The influence of the water cement ratio on the heat of hydration of portland cement per gram of cement is given in Figure 1. The second peak is developed between 2 and 34 hours after mixing. The heat developed during this peak is high when the water cement ratio is low.

When interpreting these data, it should be remembered that part of the heat developed by a hydrating paste is used for heating the paste (there must exist a temperature difference between paste and constant temperature heat sink in order to make $a$ 
heat flow possible). From calibration experiments, the heat flow recorded can be related to the temperature gradient existing over the heat flow meter; the temperature differences are found to be small, e.g. at the top of the second peak in Figure 1: $0.11{ }^{\circ} \mathrm{C}$ in the experiment with $\mathrm{w} / \mathrm{c}$ ratio $=0.2$, and $0.08{ }^{\circ} \mathrm{C}$ in the experiment $w i$ th $w / c$ ratio $=0.6$. Consequently, only a small fraction (about $2 \%$ ) of the total heat developed is employed for heating the hydration paste; thus, differences in heat capacities of paste + container caused by varying $w / c$ ratios do not noticeably influence the accuracy of the heat evolution rate measurement. Moreover, the heat capacities do not differ much since they are determined largely by that of the containers.

Therefore, it must be concluded from the results mentioned in Figure 1, that the hydration reaction connected with the second heat evolution peak ( $C_{3} S$ hydration) is faster in pastes of lower $w / c$ ratio. This stands in contrast with data reported by Kantro and Copeland (6) but agrees with experiments reported by Locher (7).

A slower $C_{3} S$ hydration with increasing $w / c$ ratio can be attributed to the influence of $C_{3} A$ hydration. When a high $w / c$ ratio is used, more $C_{3} A$ reacts with water in the initial stages before the $C_{3} A$ is covered with ettringite, and more material dissolves, so more aluminium is taken up by the calcium-silicate hydrates formed on the $\mathrm{C}_{3}$ Sgrains, shielding them from water. At low $\mathrm{w} / \mathrm{c}$ ratio the $C_{3} A$ will reoct less because the layer of ettringite is built up sooner around these grains since the water is super-saturated more quickly.

With this mechanism, a large influence of mixing conditions and cement composition is comprehensible, which explains the contradictory findings reported concerning the influence of $w / c$ ratio on the hydration rate of $\mathrm{C}_{3} \mathrm{~S}$. 
The third peak is higher for higher $w / c$ ratio and there is a small shift to shorter times. This difference can be explained by a difference in morphology of the ettringite formed.

At low w/c ratio $(<0.30)$ a closely packed ettringite layer is formed. The layer formed at higher $w / c$ ratio consists of ettringite with a more needle-like structure, which is less dense. This layer is less able to cut off the $C_{3} A$ grains from the supply of water. Thus at high $\mathrm{w} / \mathrm{c}$ ratio the process of water transport through the ettringite layer elapses faster; sulphate is consumed sooner and an unhindered $\mathrm{C}_{3} \mathrm{~A}$ reaction can start.

The resulting third peak will be higher at higher $w / c$ ratio because more water is available and less hydrosilicates have been formed (as evidenced by the lower second peak), and the silicate hydrates formed may be less dense, so the water transport to the grains is less hindered. This third peak is not seen at very low $\mathrm{w} / \mathrm{c}$ ratios because the low amount of water is completely blocked from the $\mathrm{C}_{3} \mathrm{~A}$ by the higher amount of $\mathrm{CSH}-\mathrm{gel}$ formed during the second peak. The hump on the second peak ot these $w / c$ ratios can be attributed to the reaction of $\mathrm{C}_{3} \mathrm{~A}$ at a stage where the ettringite layer is repaired after bursting through crystallization pressure (see also shrinkage measurements).

At the start of the investigations it was found that measurements on the same cement with the same $\mathrm{w} / \mathrm{c}$ ratio in various tests at different times gave different heights of the peaks and different times of occurrence. This was thought to be caused by the influence of humid air during storage. To prove this, a batch of portland cement was exposed to air with different amounts of $\mathrm{CO}_{2}$ and water during different periods. The moisture from the oir reacts with $\mathrm{C}_{3} \mathrm{~A}$ and $\mathrm{C}_{3} \mathrm{~S}$, the product reacts with $\mathrm{CO}_{2}$. This was shown by infra-red spectroscopy, where the band of the calciumsulphate decreases with the band of anhydrous calcium-aluminate 
FIG. 4

The disappearance of anhydrous calcium-aluminate by exposure to $\mathrm{CO}_{2}$ and humid air

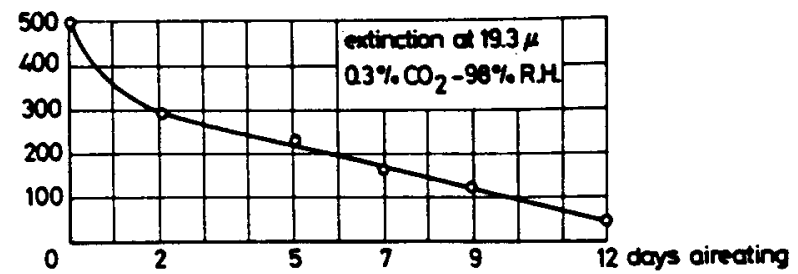

at $19.3 \mu \mathrm{m}$, indicating that calcium-sulpho-aluminates and/or calcium-carbo-aluminates are formed (see Figure 4).

The total heat development of a paste from oerated cement (Figure 5) is decreasing with increasing aerating time especially at the more humid conditions $(>44 \% \mathrm{r} . \mathrm{h}$.$) . The second peak decreases and dis-$ appears at longer aerating times. The third peak is formed sooner. These peaks are very sharp.

In view of these effects, care was taken that aerating of the cement used in the other investigations could not take place. The strength of hardened paste or mortar made with aerated cement was very low.

The influence of quartz sand on the flow of heat of portland cement is given in the Figures 6 and 7 for w/c ratios of 0.50 and 0.30 . The addition of sand influences predominantly the third peak. The peak becomes smaller and occurs sooner when the amount of sand is increased.

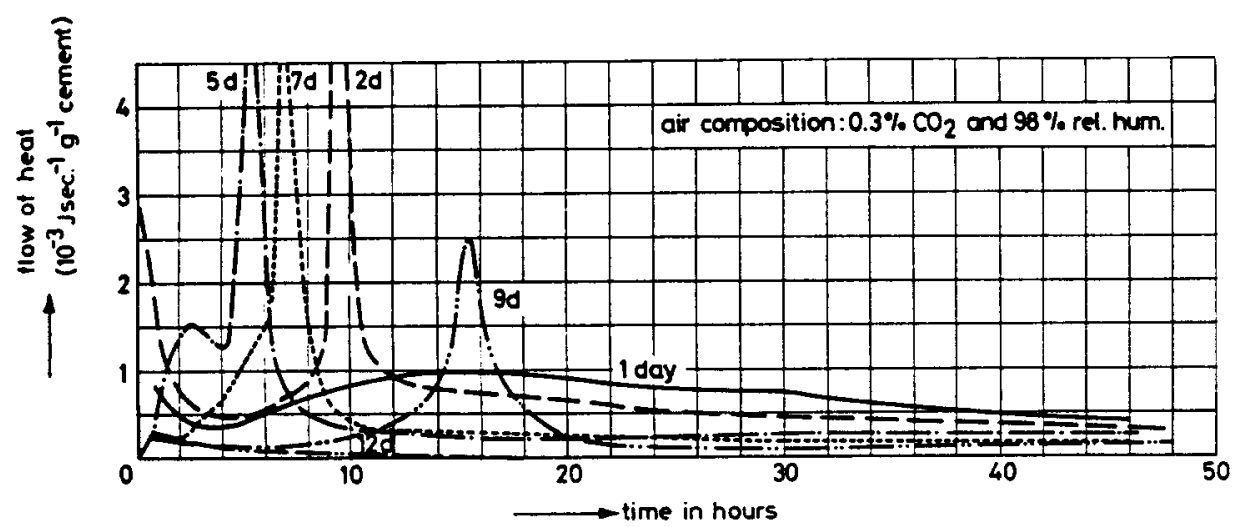

FIG. 5

Heat development of portland cement ofter aerating for a number of days 


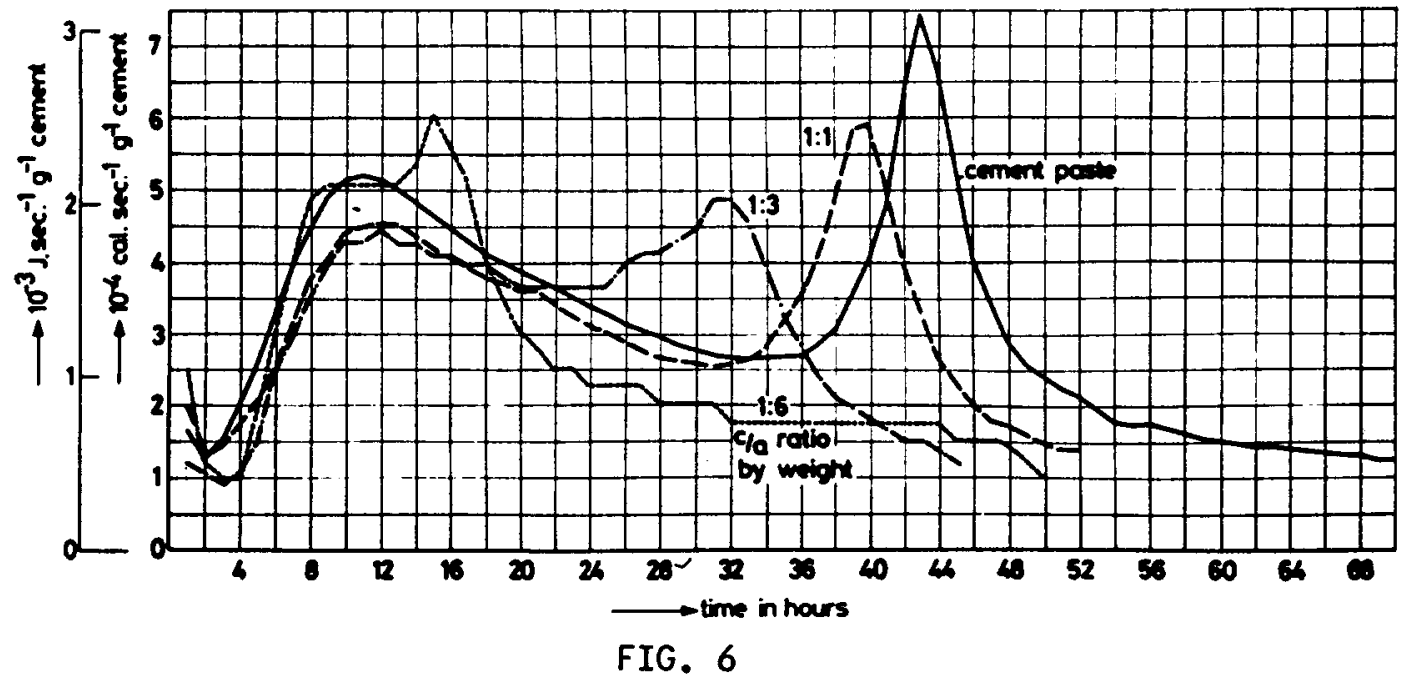

Flow of heat of portland cement with different amounts of quartz sand ( $w / c$ ratio 0.50 ) (cement-aggregate ratio by weight $1: 0 ; 1: 1 ; 1: 3$ and $1: 6)$

The first minimum comes later, indicating that the first peak lasts longer, so less $C_{3} A$ is available to produce the third peak. The sulphote consumption must be faster too, which results in a shift to shorter times for this peak. It is not clear how the sand influences the early $C_{3} A$ reaction. The following explanations are possible:

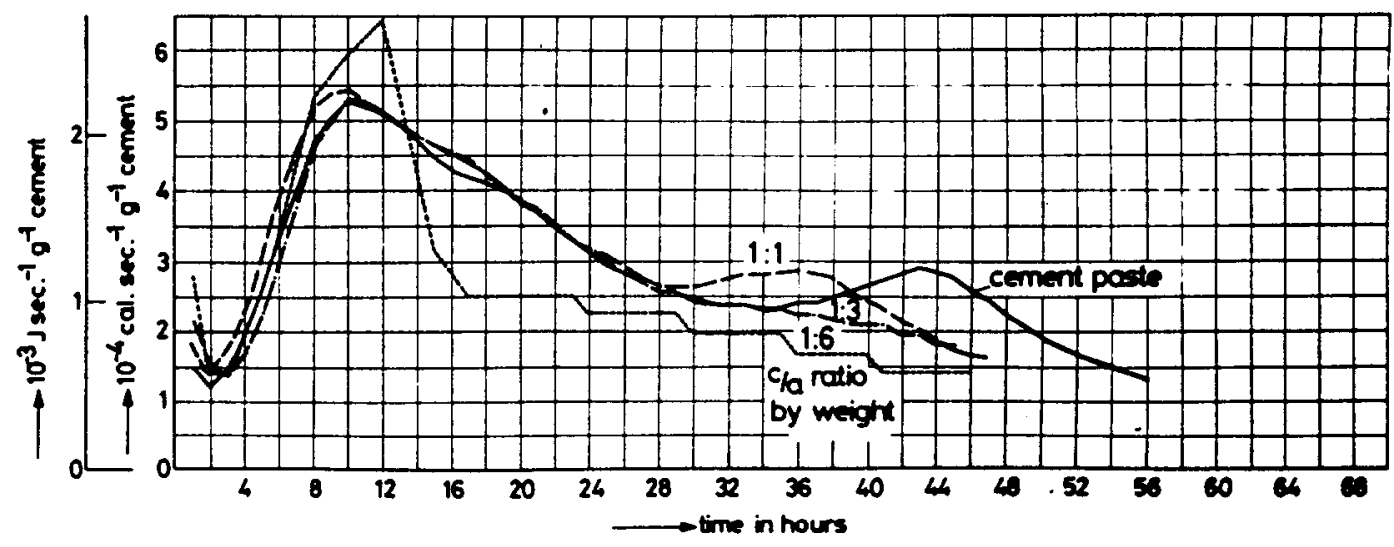

FIG. 7

Heat development of portland cement with quartz sand ( $w / c$ ratio $0.30, c / a$ ratio by weight $1: 0$; 
a) Sand gives nuclei for crystallization

b) Sand absoribs the sulphate

ad a) The products of the $\mathrm{C}_{3} \mathrm{~A}$ reaction ( $\mathrm{C}_{2} \mathrm{AH}_{8}, \mathrm{C}_{4} \mathrm{AH}_{14}$ and ettringite) can be formed in the vicinity of the sand when the crystallization of these products form faster by nuclei given by the sand. By this the $C_{3} A$ can react longer and faster, so sulphate is consumed more quickly. The outcome of this will be that the third peak is developed sooner and will be smaller. As $C_{3} A$ grains react longer, the $C_{3} S$ grains will be coated with more hydro-aluminates too, so the second peak will be retarded.

The fact that $C_{3} A$ reacts longer under the influence of sand can be proved by integrating the first peak in the flow of heat curve which was not possible with the method used.

ad b) Sulphate absorption is not likely because experiments on mortars with a cement/aggregate weight ratio of $1: 1$ with different gradings (ranging from $16-200 \mathrm{~cm}^{2} / \mathrm{g}$ ) of the sand did not show an influence of the surface of the sand.

\section{Velocity of Ultrasonic Pulses}

Up to the time at which the top of the second peak in the flow of heat curve took place, the pulse velocity was higher for higher $w / c$ ratios (Figure 8 and 9 ).

After this period the pulse velocities were higher for lower w/c ratios. When the velocity is thought to be correlated to the compressive strength, the early strength of a paste or mortar made with high $w / c$ ratio must be higher than one made with a low $w / c$ ratio. During the first hours the velocities, however, were very low, even lower than in water, so the velocity was at that stage not directly related to the strength. An explanation for these low velocities was given by Dr. E. Drescher 


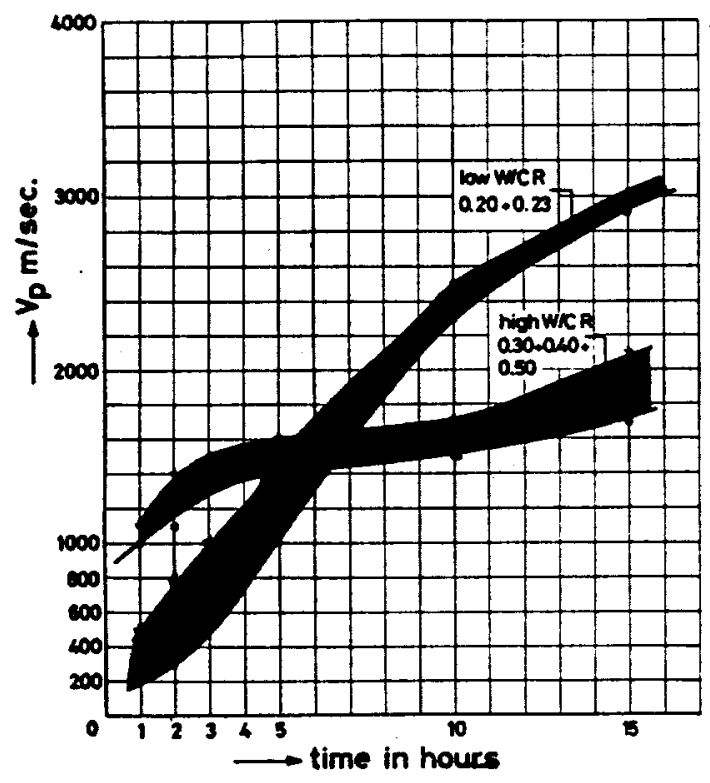

FIG: 8

Pulse velocity in pastes with different $w / c$ ratio

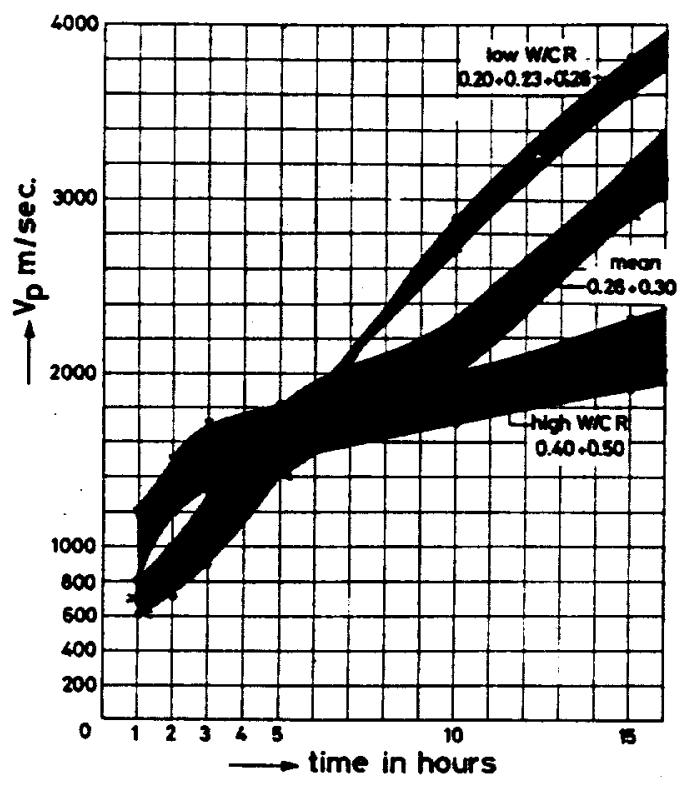

FIG. 9

Pulse velocity in mortar (c/a ratio $1: 1$ ) with different $w / c$ ratio

from Poland, when working in the Netherlands, by considering the cement paste as a visco-elastic material, using a Maxwell model. According to this, the velocity is depending on the frequency of the pulse (see Figure 10). At low frequencies (till $500 \mathrm{kHz}$ ) there is a large influence of the viscous part of the model by which the velocities are very low during the first 10 hours. For higher frequencies $(2000-4000 \mathrm{kHz})$ the velocity is much nearer to the velocity of sound in water. At these frequencies the elastic part is the most important.

After 10 hours the differences between the velocities are smaller but the velocities are still higher for higher frequencies. At the same frequency the curves for the higher and lower $w / c$ ratio cross each other, but the time at which they cross is not the same, more details have to be obtained however.

From this model the conclusion is drawn that the velocity in paste and mortar during the first hour is to a high degree dependant on 


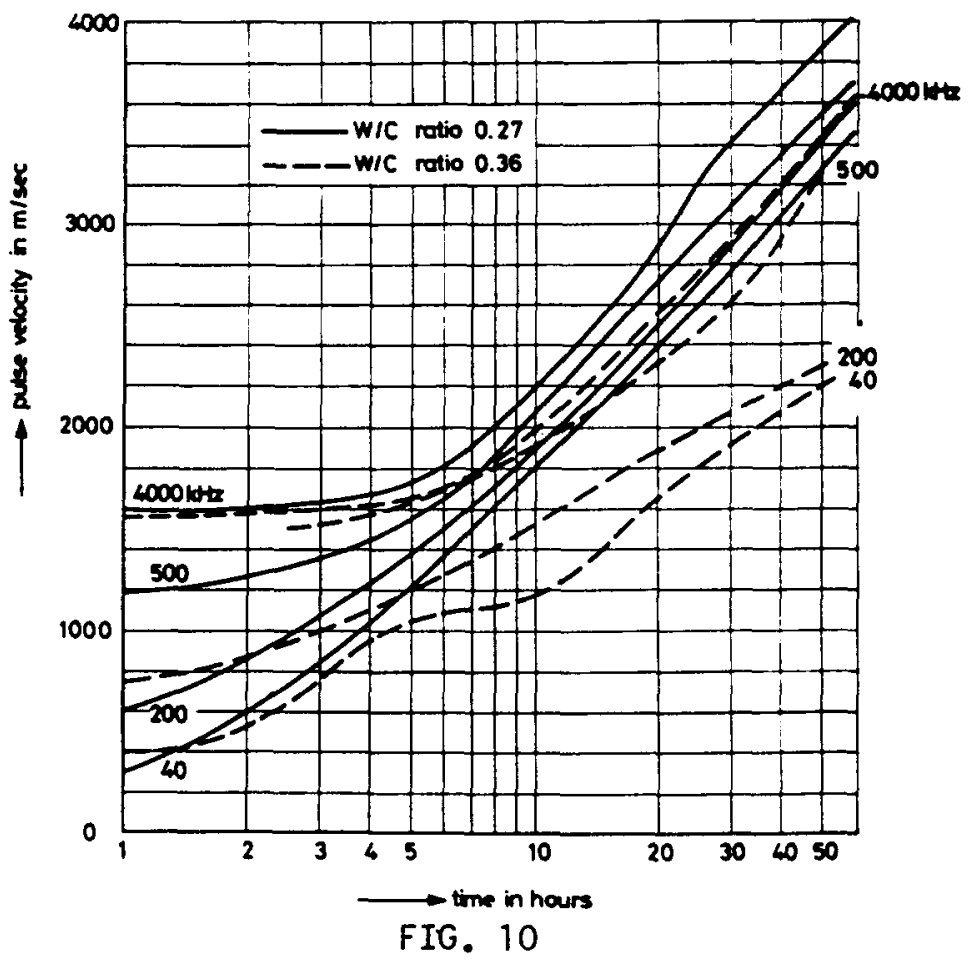

Pulse velocity in paste as a function of the time for different pulse frequencies (experimental)

internal viscous forces. These forces are formed by the interaction of particles together and particles with fluid. The particles change in number, form and mass during the hardening process. The fluid changes in viscosity by the dissolving clinker minerals. Sn the difference in velocity between paste or mortar made with either low or high $\mathrm{w} / \mathrm{c}$ ratio can probably be attributed to the difference in morphology of ettringite, the degree of hydration of $\mathrm{C}_{3} \mathrm{~A}$ and the degree of supersaturation of the water. Later this difference disappears because more particles are formed, during the second peak, giving a more solid gel with more elastic properties*).

*) A pulse can be seen as an external force working on the paste. At low $\mathrm{w} / \mathrm{c}$ ratio a paste is called dilatant, the opposite of thixotrope, so an external force induces more internal force, that is a more viscous behaviour, resulting in a low velocity. At high w/c ratio the poste is thixotrope so an external force gives an abolition of the viscous forces resulting in higher velocities during the first hours. 
This is particularly distinct in low $\mathrm{w} / \mathrm{c}$ ratio pastes: here particle to particle interaction would be higher than in high $\mathrm{w} / \mathrm{c}$ ratio postes at the same degree of hydration because of the latters' higher porosity; moreover, according to the large heat evolution rate during the second peak more silicate hydrate is formed in low $\mathrm{w} / \mathrm{c}$ ratio pastes. Mortars have always higher pulse velocities than pastes at the same $\mathrm{w} / \mathrm{c}$ ratio because more "solid material" is found per unit of volume.

\section{Shrinkage}

In Figures 11 and 12 the shrinkage curves combined with the pulse velocity and flow of heat are given for paste and mortar with a cement : aggregate weight ratio $1: 1$. Different $w / c$ ratios were used. During the first hours until the time at which the second peak is fully developed, the shrinkage is larger at lower $\mathrm{w} / \mathrm{c}$ ratio. Later the shrinkage becomes lower for the lower $w / c$ ratio so the curves cross each other during the second peak. This is ascribed to the following mechanism:

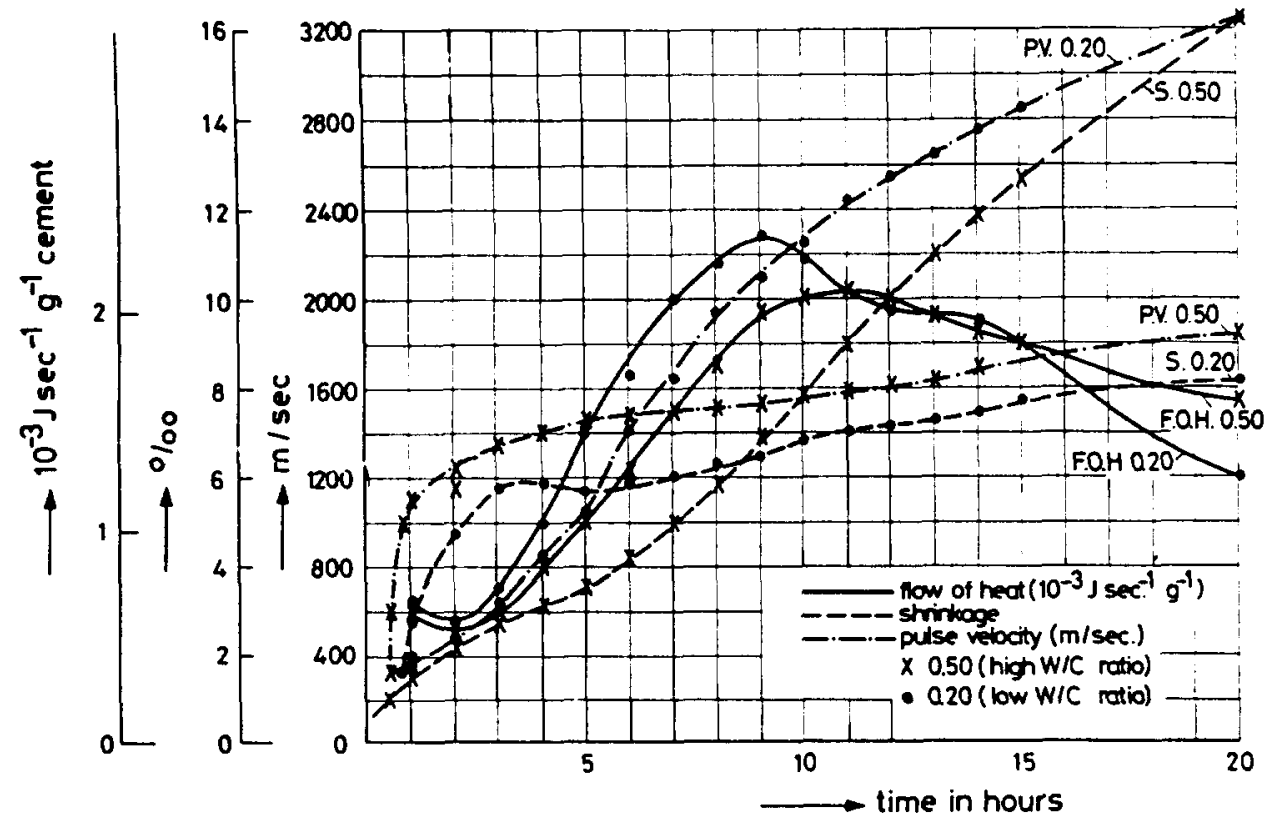

FIG. 11

Combined curves of flow of heat, shrinkage and pulse velocity for pastes 
Vol. 5 , No. 4

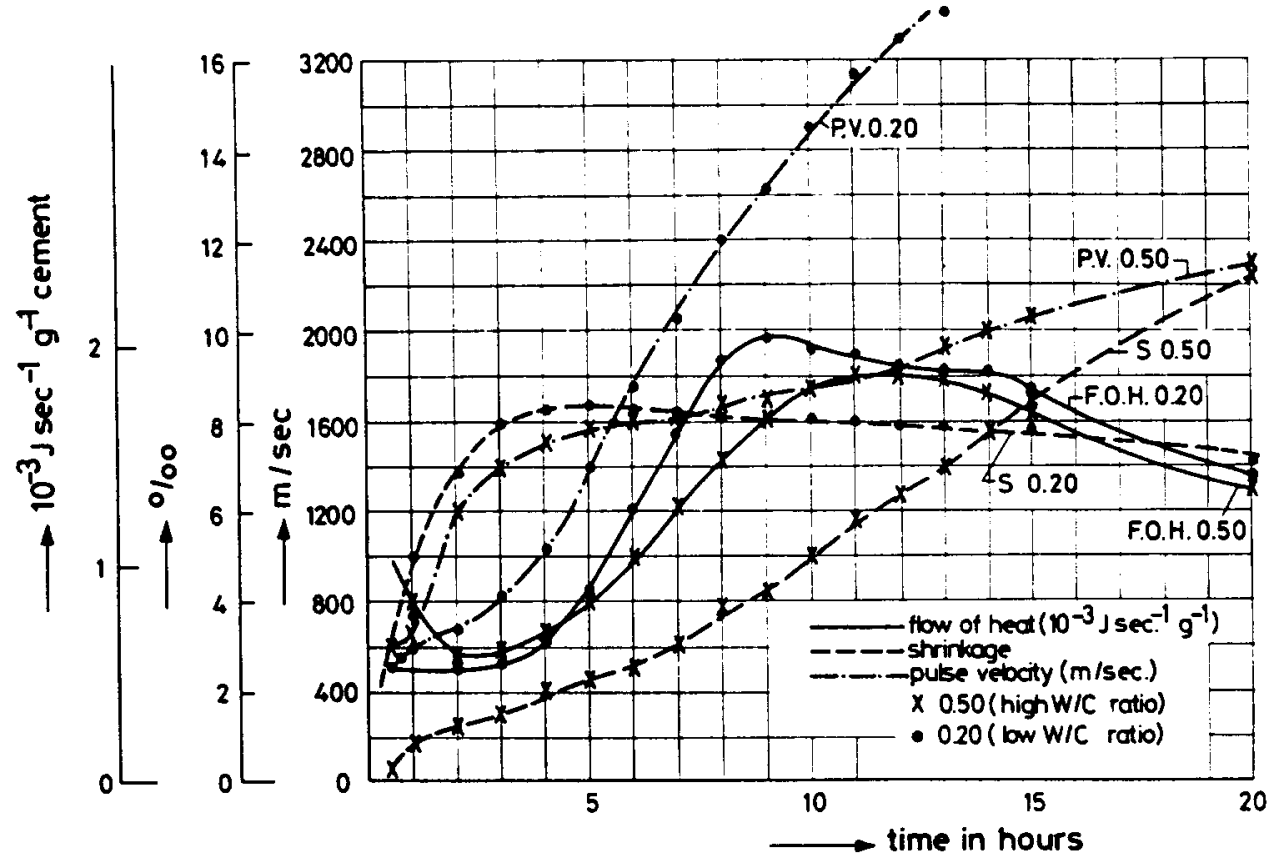

FIG. 12

Combined curves of flow of heat, shrinkage and pulse velocity for mortar ( $c / a$ ratio $1: 1$ )

Directly after mixing $C_{3} A$ dissolves, giving a fast shrinkage (Figure 13). After some time the ettringite crystals are formed, $C_{3} A$ dissolves more slowly and the velocity of shrinkage decreases.

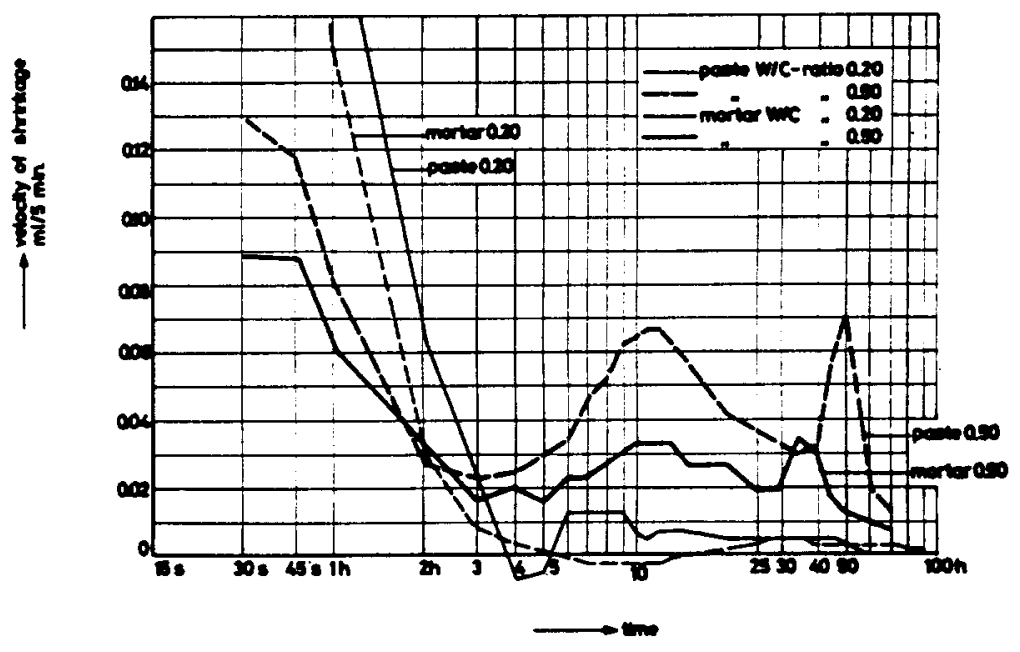

FIG. 13 .

Velocity of shrinkage of paste and mortar 
The formation of ettringite compensates for the shrinkage because the volume of ettringite is only a little smaller thon the total volume of the starting materials, while all other hydrates have a much smaller volume than the starting materials.

At low $w / c$ ratios the ettringite crystals are formed close around the $C_{3} A$ and the $C_{3} S$ reaction starts early. After approximately 4 hours the unstable CSH-gel is formed causing an increase of the velocity of shrinkage. When the $\mathrm{C}_{3} \mathrm{~S}$ reaction is at its maximum value the velocity of shrinkage decreases while stable CSH-gel is formed. When the hump on the second peak occurs the velocity of shrinkage gets a small decrease that is followed by an immediate increase after this shoulder. This effect can be explained by the formation of shrinkage resisting ettringite during the stage at which the bursted coating is sealed around the $C_{3} A$ grain. At high water cement ratios, shrinkage is less compared with low $w / c$ ratios (Figure 11 ). This is supposed to be caused by the different morphology of the ettringite that has been formed. More $C_{3} A$ has reacted but shrinkage is less so the ettringite formed must have more shrinkage resisting properties than the ettringite formed at low $\mathrm{w} / \mathrm{c}$ ratio. When the crystals are longer and are more perpendicular to the grain they can keep the grains wider apart. After 10 hours, shrinkage becomes higher at high $\mathrm{w} / \mathrm{c}$ ratios than at low $w / c$ ratios.

This can be attributed to differences in porosity of the CSH-gel: at the same degree of hydration the interaction between the calcium-silicate hydrate porticles would be lower at higher $\mathrm{w} / \mathrm{c}$ ratio than at lower $w / c$ ratio, resulting in a weaker total system; in the pastes investigated here this is enhanced by a higher degree of $\mathrm{C}_{3} \mathrm{~S}$ hydration in low $\mathrm{w} / \mathrm{c}$ ratio pastes as evidenced by the high heat evolution rate during the second peak.

When the third peak in the flow of heat curve appears, the velocity of shrinkage becomes faster again. This is caused by the hydration 
of $\mathrm{C}_{3} \mathrm{~A}$. Probably the shrinkage is even boosted up by the transformation of ettringite in the less voluminous monosulphote and aluminates. The tobermorite gel is not strong enough at this stage to withstand this shrinkage. Moreover, the new components may form in a less stress state or in low stress locales within the sample and therefore will not provide the support which the ettringite has previously provided.

The influence of quartz sand on the shrinkage is as follows: During the first hours a mortar with $c / a$ weight ratio $1: 1$ shrinks more than a paste with the same $w / c$ ratio. After \pm 8 hours the shrinkage of a mortar is less (the curve in Figure 12 is an extension to the rule). The shrinkage curves for low and high $\mathrm{w} / \mathrm{c}$ ratios cross each other during the formation of the second peak. The explanation for this is the same as that given for paste. The higher value of the shrinkage of mortar than of paste during the first hours can be explained if it is admitted (see flow of heat) by the fact that the sand has a large influence on the morphology of the ettringite formed. At low $\mathrm{w} / \mathrm{c}$ ratio the compact coating around the $C_{3} A$ is not formed, $C_{3} A$ reacts longer causing greater shrinkage. The shrinkage retaining influence of the ettringite at higher $\mathrm{w} / \mathrm{c}$ ratio is partly maintained. Shrinkage is less in relation to mortar with low $\mathrm{w} / \mathrm{c}$ ratio but there is more shrinkage compared with paste with the same $w / c$ ratio, notwithstanding the larger amount of solid material per unit of volume.

As a consequence of the observed influence of the sand on shrinkage, a large dependance of the shrinkage on the specific surface of the sand was expected. But the measurements on mortar 1:1 with different gradings of the sand (from $16-200 \mathrm{~cm}^{2} / \mathrm{g}$ ) gave no clear relation between these quantities. So the explanation for the influence of sand needs more research as does the explanation for the influence of sand on heat evolution. 


\section{Conclusions}

The measurements of the flow of heat, shrinkage and pulse velocity show that during the hardening a clear difference exists between pastes or mortars made with eigher high or low water/cement ratio. During the second peak in the heat evolution, a change takes place in the course of the shrinkage and pulse velocity. High starting values become low ones and low starting values become high. For these effects two explanations may be envisaged. One is as follows:

At low water cement ratios the ettringite formed during the first peak is thought to consist of a great number of small crystals that form a compact layer close around the $C_{3} A$ grain hindering the further reaction of the $\mathrm{C}_{3} \mathrm{~A}$. This gives high shrinkage and low pulse velocity. High shrinkage because all particles can come closer to each other and a low pulse velocity because the viscous forces in this compact system are larger.

At high water cement ratios the ettringite has the possibility to form more needle-like crystals that are able to keep the clinker particles wider apart thus retaining shrinkage and giving a more "elastic" network in wich pulses can proceed faster.

Alternatively, the low pulse velocity in the initial stages in low water cement ratio pastes could be ascribed to formation of hydrate layers in the vicinity of the contact points between the solid particles.

Then the solid particles do not move independantly under the action of an ultrasonic pulse, and damping may occur especially in the transmission of motion from one particle to its neighbour. The low pulse velocity in the initial stages in low w/c ratio pastes should then be ascribed to a relative large extent of hydration (as evidenced by the heat evolution rate data), which causes a large amount of hydrate crystals (rather flexible in this state) to surround the contact points. In the later stages, the hydrate crystals 
obtain so many mutual contact points that they obtain together a certain elastic stiffness; then the pulse velocity is increased by a higher extent of hydration. Future research is needed for settling this point.

During the second peak in the flow of heat curve, the CSH-gel is formed. At low $w / c$ ratio a gel with good mechanical properties is formed, that resists the shrinkage better than the gel formed at high $\mathrm{w} / \mathrm{c}$ ratio. This stronger gel is more elastic; the pulse velocity becomes higher.

The $\mathrm{CSH}-g e l$ formed at high $\mathrm{w} / \mathrm{c}$ ratios is also less able to resist the extra shrinkage that occurs during the third peak, where $C_{3} A$ reacts and ettringite is transformedinto other products with a smaller volume, such as monosulphate.

The influence of the $\mathrm{w} / \mathrm{c}$ ratio gives the same trends for mortars as for pastes. The presence of quartz sand, however, influences the formation of ettringite, this results in deviations in the measured values in heat flow, shrinkage and pulse velocity compared with paste.

In the heat flow the third peak comes sooner and has a lower intensity, because the $C_{3} A$ reacts longer in the first hours, perhaps through nucleation by the sand. This first $C_{3} A$ reaction gives higher shrinkage in the early hours too.

The pulse velocity is then higher, partly because the morphology of the ettringite is not the same as in paste, especially at low w/c ratios, or because contact points between quartz particles ore less effected by hydrate formation than contact points between cement particles.

Later on, after the second peak, the sand serves as an inert aggregate and resists the shrinkage by the cement and makes possible higher pulse velocities.

The mechanism by which the sand influences the $C_{3} A$ reaction during the first hours needs more detailed study. 
The conclusion from these investigations is that good mechonical properties of pastes and mortars can be obtained when during the first five hours of hardening the shrinkage is relatively high, so that after this plastic stage one can expect low shrinkage and high pulse velocities ( $=$ high strength). This can be accomplished by promoting the growth of compact ettringite around the $C_{3} A$ grain or by suppressing ettringite formation by diminishing the $C_{3} A$ content. By this $\mathrm{C}_{3} S$ can give more tobermorite and so strength will be built up sooner.

\section{Research on hardened Paste and Mortar}

Simultaneously with the preparation of the samples for the afore cited research, prisms of $4 \times 4 \times 16 \mathrm{~cm}^{3}$ were made. Prisms which were used for determination of flexural and compressive strength were stored during 28 days in water of $20^{\circ} \mathrm{C}$. Prisms for shrinkage measurements were stored during 91 days at $20{ }^{\circ} \mathrm{C}$ and $65 \%$ relative humidity, after this period they were tested for strength. Strength and shrinkage of paste and mortar were related to the water cement ratio logarithmically (see Figure 14), and to the amount of gypsum (Figure 15) and of $C_{3} A$ (Figure 16) in portland cement.

At optimum gypsum content the strength is maximal and the shrinkage minimal (see Figure 15).

At other amounts of gypsum than the optimum amount, the water cement ratio of the sample has a larger influence on the strength and the shrinkage:

Athigher $w / c$ ratio $(\geqslant 0.40)$ a high gypsum content gives relatively low strength. High shrinkage occurs when the amount of gypsum is low at high water cementratio. When the gypsum content is nearly constant increasing amounts of $\mathrm{C}_{3} \mathrm{~A}$ give higher strengths but above $10 \% C_{3} A$ shrinkage increases excessively, independant of the $\mathrm{w} / \mathrm{c}$ ratio (Figure 16). Measurements on different types of cement showed that aluminous cement shrinks the least, while normal blastfurnace 
slag cement shrinks most at all water cement ratios.

The sequence in decreasing shrinkage of the types of cement becomes

for pastes and mortars:

Portland blast-furnace slag cement class A

Portland cement class A

Portland blast-furnace slag cement class $B$

Portland cement ciass $B$

Portland cement class $C$

High-alumina cement

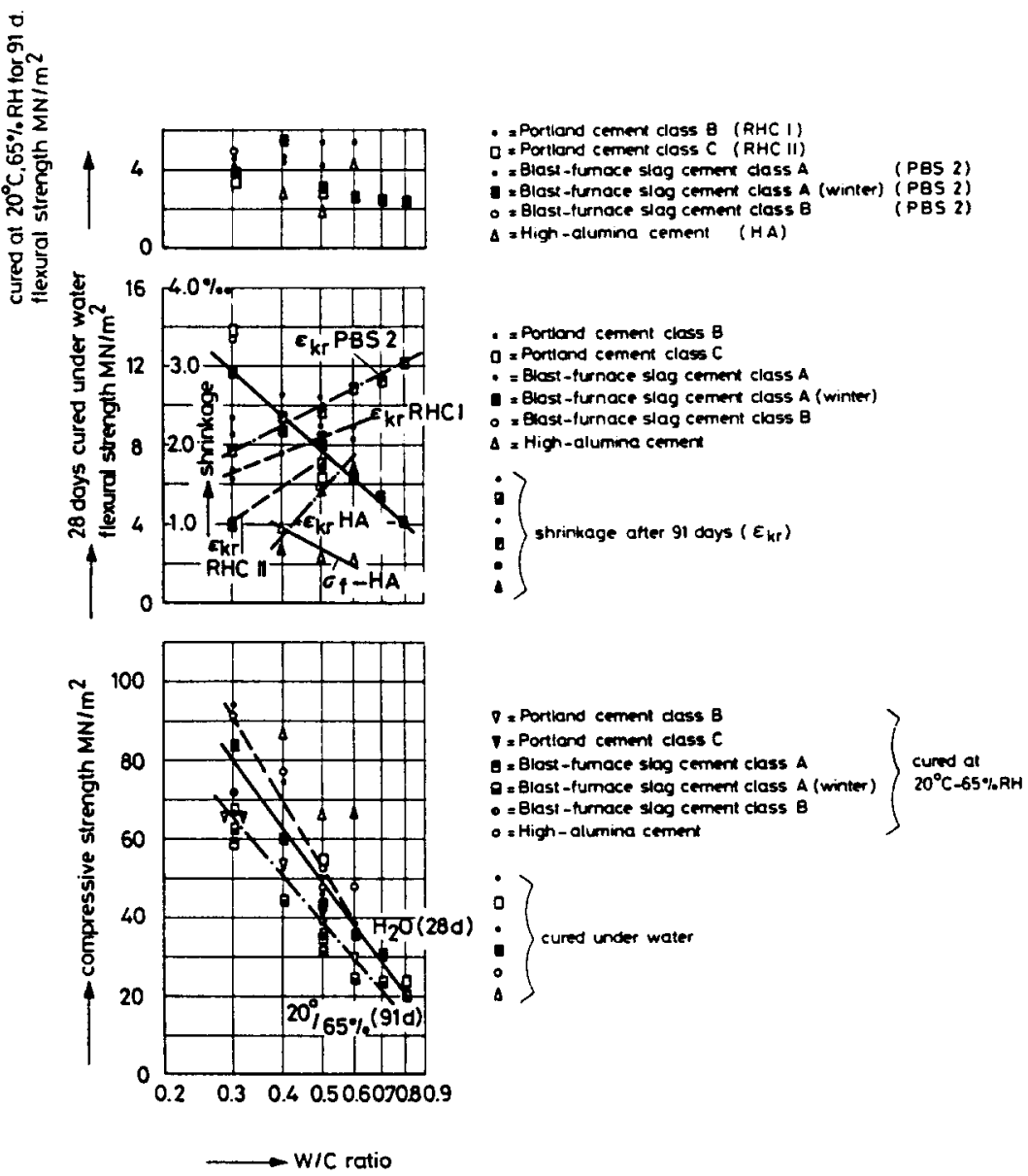

FIG. 14

Strength and shrinkage of cement-stone made from portland cement class $B$ and $C$, portland blast-furnace slag cement class $A$, $A$ winter quality and $B$ and high-alumina cement 


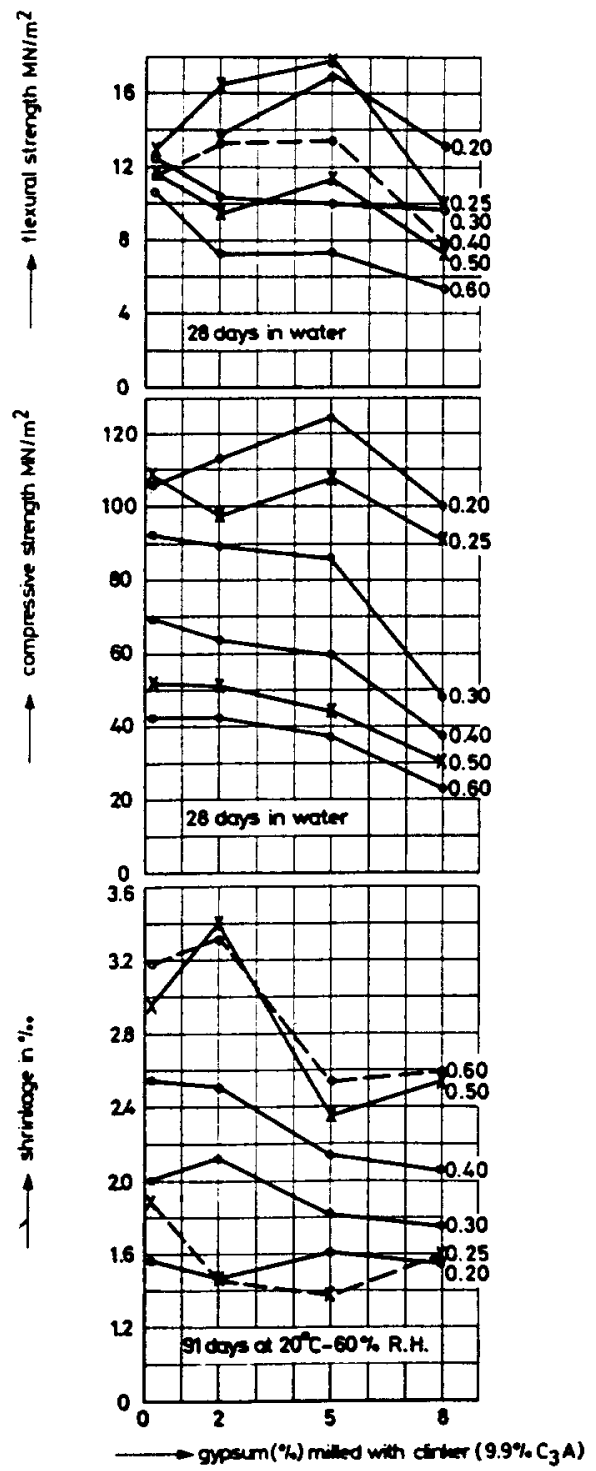

FIG。 15

Strength and shrinkage of cement-stone made from portland cement clinker and 2,5 and $8 \%$ gypsum

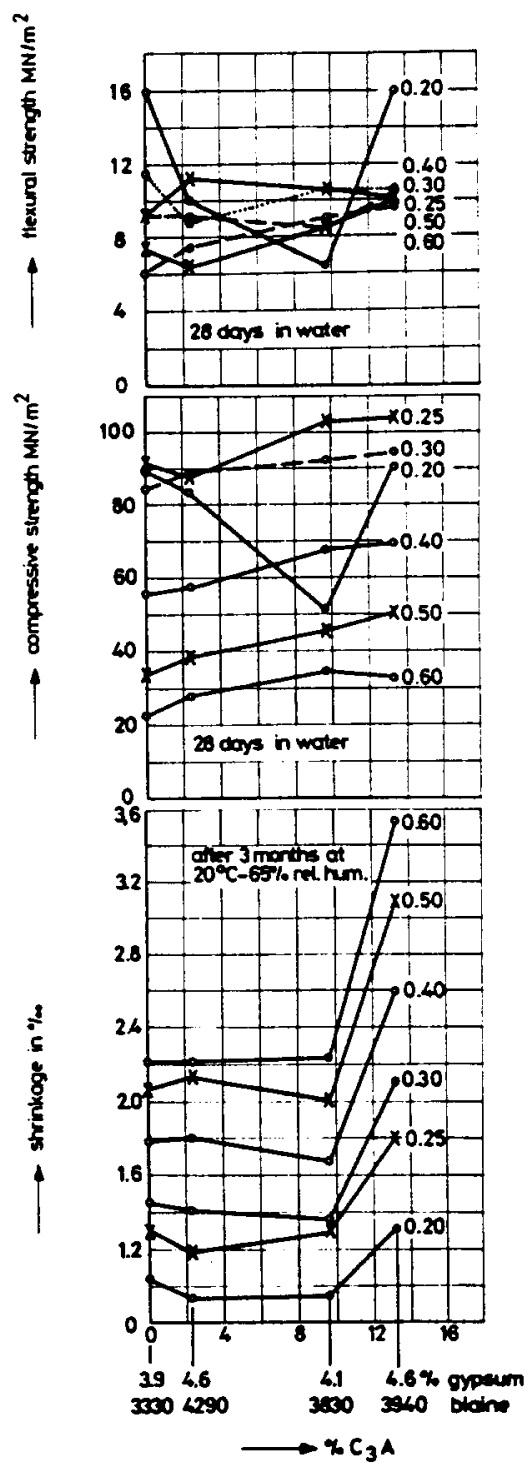

FIG: 16

Strength and shrinkage of cement-stone made from portland cement with different amounts of $\mathrm{C}_{3} \mathrm{~A}$

When the aggregate cement ratio gets higher both strength and shrinkage become lower, so cement-stone has the highest strength and highest shrinkage.

In Figure 17 the ratio compressive strength to flexural strength 


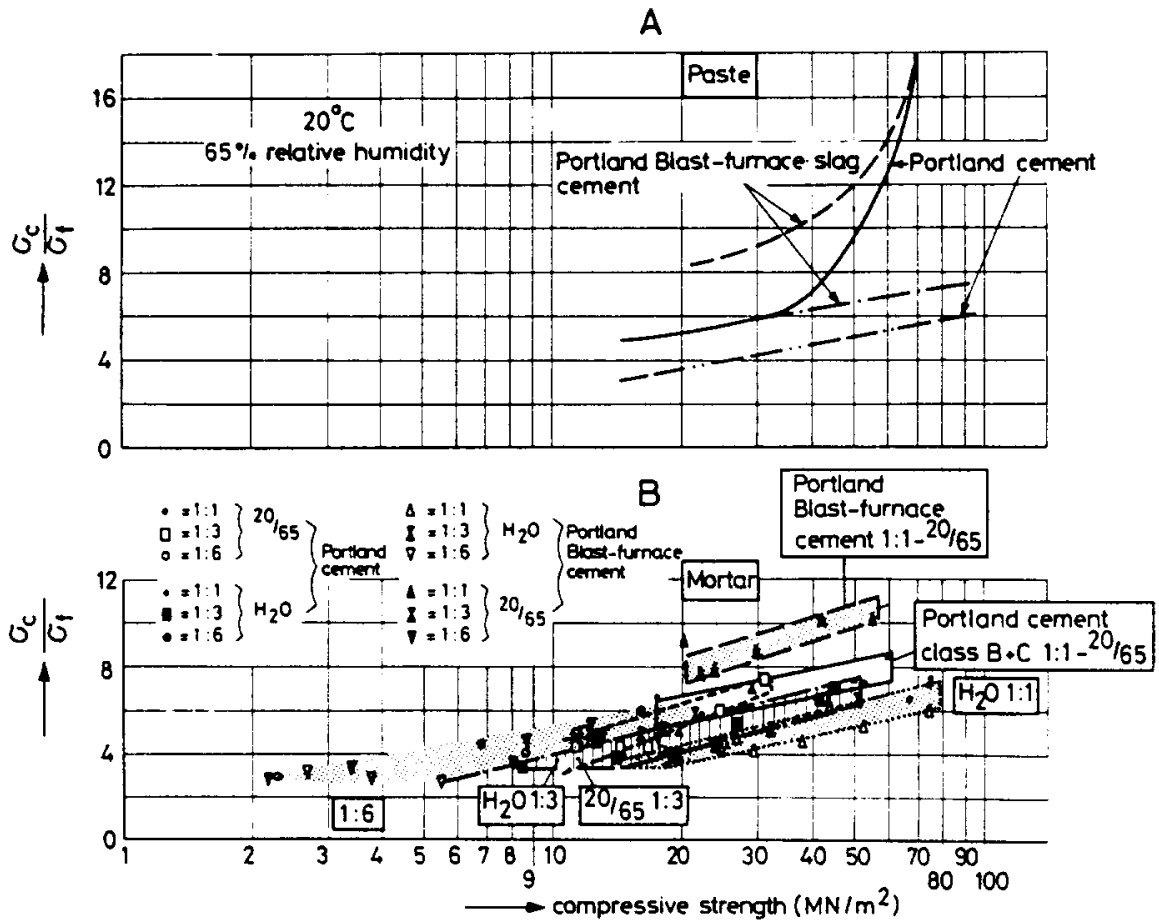

FIG. $17 \mathrm{~A}$ and $\mathrm{B}$

Ratio compressive strength: flexural strength $\left(\frac{\sigma_{C}}{\sigma_{f}}\right)$ for paste and for mortar with different aggregate to cement ratio from portland cement and portland blaist furnace slag cement cured in water at $20{ }^{\circ} \mathrm{C}$ and $65 \%$ relative humidity

$\left(\frac{\sigma_{c}}{\sigma_{f}}\right)$ that may be important concerning crack formation in concrete, is given as a function of the compressive strength. The $\frac{\sigma_{c}}{\sigma_{f}}$ ratio was always higher for cement pastes with blastfurnace slag cement than with portland cement class $A$, after hardening in woter.

The difference between blast furnace slag and portland cement paste hardened under dry conditions ( $20^{\circ} \mathrm{C}, 65 \%$ r.h.) was considerably higher ( \pm 2 times) at low compressive strength than at high strength, where the difference disappeared gradually (Figure 17A). The ratio $\frac{\sigma_{C}}{\sigma_{f}}$ at dry conditions was always higher than the ratio for samples stored under water. The difference increased at higher compressive strength of the cement-stone. 
For mortars with an aggregate cement ratio of $1: 1$ the type of cement when hardened under water had no influence on the ratio $\frac{\sigma_{c}}{\sigma_{f}}$ (Figures $17 A$ and $B$ ). At dry conditions blast-furnace slag cement had approximately $30 \%$ higher values for $\frac{\sigma_{C}}{\sigma_{f}}$ than portland cement.

At the aggregate cement ratio of 3 there was no difference between the types of cement although the ratio again was higher under dry conditions than under water. At the aggregate cement ratio of 6 no difference could be found either between the types of cement or between the conditions. These systematics are interesting with respect to the outermost layer or skin of concrete where a transition in aggregate cement ratio from 6 or 7 to 0 occurs, going from the inside to the surface. At high flexural and compressive strengths of the bulk concrete the flexural strength of the skin of concrete can change considerably, especially under dry conditions, through a decrease of the aggregate cement ratio of the concrete + outermost layer, taking into account the large influence of the type of cement used.

Only very good curing and a low water cement ratio can make it possible that the flexural strength of the outermost layer of concrete made with blostfurnace cement is not lower than if made of portland cement (at the same compressive strength). In case of both, surface corrosion and mechanical load (as in frost damage), the use of blastfurnace cement may lead to faster surface corrosion than the use of portland cement with the optimum amount of gypsum at equal compressive strength.

\section{Acknowledgement}

The authors gratefully acknowledge the receipt of a grant from the Netherlands Committee for Concrete Research (CUR). Full details of the work described in this paper can be obtained from the secretariat of the Commission BlO, c/O IBBC-TNO, P.O. Box 49, Delft, The Netherlands. 


\section{References and bibliography}

1) W. Lerch, Proc. Am. Soc. Test. Mat. 46, 1252 (1946)

2) H.N. Stein, Silicates Industriels $\underline{28}$ (3), 141-5 (1963)

3) H.E. Schwiete, U. Ludwig, P. Jăger, Zement-Kalk-Gips 17, 229 (1964)

4) P. Seeligmann and N.R. Greening, Highway Research Record $\underline{26}, 80$ (1964)

5) H.N. Stein, J. Appl. Chem. (London) 15, 314 (1965)

6) D.L. Kantro and LoE. Copeland, Proc. 5th Int. Symp. Chem. Cement, Tokyo 1968, Vol. II p. 387

7) F.W. Locher, Symposium on Structure of Portland Cement Paste and Concrete, Highway Research Board, Special Report 30 , p. 300 